\title{
Workshop on Interacting with Smart Objects
}

\author{
Melanie Hartmann, Daniel Schreiber, Max Mühlhäuser \\ Telecooperation Group \\ Technische Universität Darmstadt, Germany \\ \{melanie, schreiber, $\max \}$ atk. informatik.tu-darmstadt.de
}

\author{
Oliver Brdiczka \\ Palo Alto Research Center (PARC), USA \\ oliver@parc.com
}

\begin{abstract}
The number of smart objects in our everyday life is steadily increasing. In this workshop we discuss how the interaction with these smart objects should be designed from various perspectives.
\end{abstract}

\section{Author Keywords}

Smart Objects, Interaction Design, User Studies, Tangible Interaction, Ubiquitous Computing

\section{ACM Classification Keywords}

H.1.2 User/Machine Systems: Human Factors.

\section{General Terms}

Design, Human Factors

\section{INTERACTING WITH SMART OBJECTS}

There is an undeniable ongoing trend to put computing capabilities into everyday objects, turning them into smart objects [3]. Well known examples range from smart kitchen appliances and objects (smart coffee machines, smart knifes and cuttings boards) $[6,4,5]$ up to smart meeting rooms [2] and even city-wide infrastructures [1].

These smart objects are fully functional on their own, but added value is obtained through communication and distributed reasoning. While other venues have focused on the many technical challenges of implementing smart objects, far less research has been done on the topic of how the intelligence situated in these smart objects can be applied to improve their interaction with the users. This field of study poses unique challenges and opportunities for designing smart interaction.

Smart objects typically have only very limited interaction ca-

Copyright is held by the author/owner(s).

IUI'11, February 13-16, 2011, Palo Alto, California, USA.

ACM 978-1-4503-0419-1/11/02.

\author{
Kris Luyten \\ Hasselt University \\ Expertise Centre for Digital Media (EDM) \\ kris.luyten@uhasselt.be
}

pabilities. Yet, their behavior exhibits an amazing amount of intelligence. For example, several digital cameras are able to recognize faces in a scene automatically and adjust the focus accordingly. For first time users this can be quite surprising, and for experts this is a feature they probably want to turn off. The challenge is to design intuitive interaction with smart objects in a way the user feels in control of the smart object and understands the behaviour and capabilities of the object.

Interaction with smart objects is situated in the physical environment of the user, i.e., it does not take necessarily place in a desktop setting. A smart object often uses additional cues from its context to improve the interaction with the user, thereby, making the interaction between user and smart object feel more natural. Furthermore, a smart object is a physical object which allows to exploit approaches from tangible and embodied interaction to enhance the interaction.

\section{WORKSHOP CONTENT}

The aim of this workshop is to leverage the discussion on the design of the interaction with smart objects. Thereby, we bring together researchers from all related fields like humancomputer interaction, ubiquitous computing and psychology. We are mostly interested in how intelligent interaction techniques can be combined with the specific characteristics of smart objects, i.e., we aim to cover:

- novel interaction concepts for smart objects

- self-explanatory smart objects

- multimodal and adapted interaction

- context-awareness

- embodied and tangible interaction

- intelligibility of smart objects

- user studies and evaluation techniques

- technology and models required for enabling the interaction with smart objects 
More information about the papers and outcome of the workshop can be found on the corresponding website

http: / / www. smart-objects.org.

\section{PROGRAM COMMITTEE MEMBERS}

We want to thank all our program committee members for their contribution:

- Aba-Sah Dadzie, University of Sheffield, UK

- Albrecht Schmidt, Universität Duisburg Essen, Germany

- Alexander Kröner, DFKI, Germany

- Alexandre Demeure, Laboratory of Informatics of Grenoble, France

- Ben Waber, MIT Media Lab, USA

- Bo Begole, PARC, USA

- Boris de Ruyter, Philips Research, Netherlands

- Daniel Olguin Olguin, MIT Media Lab, USA

- Davy Preuveneers, K.U. Leuven, Belgium

- Enrico Motta, Open University, UK

- Fahim Kawsar, Lancaster University, UK

- Fernando Lyardet, TU Darmstadt, Germany

- Geert Vanderhulst, Alcatal-Lucent Bell Laboratories, Belgium

- Gerd Kortuem, Lancaster University, UK

- Jani Mäntyjarvi, VTT, Finland

- Jeff Pierce, IBM, USA

- Jo Vermeulen, Hasselt University, Belgium

- Kristof Van Laerhoven, Technische Universität Darmstadt
- Massimo Zancanaro, FBK, Italy

- Marco Blumendorf, DAI Laboratory, Germany

- Patrick Reignier, INRIA, France

- Wolfgang Maass, University of St. Gallen, Switzerland

\section{REFERENCES}

1. Filipponi, L., Vitaletti, A., Landi, G., Memeo, V., LAURA, G., AND PUCCI, P. Smart city: An event driven architecture for monitoring public spaces with heterogeneous sensors. Sensor Technologies and Applications, International Conference on 0 (2010), 281-286.

2. Johanson, B., Fox, A., And Winograd, T. The interactive workspaces project: Experiences with ubiquitous computing rooms. IEEE Pervasive Computing 1 (April 2002), 67-74.

3. Kortuem, G., Kawsar, F., Sundramoorthy, V., AND FITTON, D. Smart objects as building blocks for the internet of things. IEEE Internet Computing 14 (2010), 44-51.

4. Olivier, P., Xu, G., Monk, A., And Hoey, J. Ambient kitchen: designing situated services using a high fidelity prototyping environment. In Proceedings of the 2nd International Conference on PErvasive Technologies Related to Assistive Environments (New York, NY, USA, 2009), PETRA '09, ACM, pp. 47:1-47:7.

5. SCHNEIDER, M. The semantic cookbook: sharing cooking experiences in the smart kitchen. In Intelligent Environments, 2007. IE 07. 3rd IET International Conference on (2007), pp. 416-423.

6. Silo, I., Mima, N., Frank, I., Ono, T., AND Weintraub, H. Making recipes in the kitchen of the future. In CHI '04 extended abstracts on Human factors in computing systems (New York, NY, USA, 2004), CHI '04, ACM, pp. 1554-1554. 